\title{
Are psychological symptoms a risk factor for musculoskeletal pain in adolescents?
}

\author{
Alessandro Andreucci ${ }^{1,2}$ - Paul Campbell ${ }^{1,3} \cdot$ Kate M. Dunn $^{1}$ \\ Received: 13 October 2020 / Revised: 31 January 2021 / Accepted: 18 February 2021 / Published online: 2 March 2021 \\ (C) The Author(s) 2021
}

\begin{abstract}
Adolescent musculoskeletal pain is common and is associated with musculoskeletal pain in adulthood. Psychological symptoms, also common in adolescence, have been shown to be associated with musculoskeletal pain, but the current evidence is mixed and may be dependent on effect modifiers. This study investigated whether adolescents with psychological symptoms (internalizing and externalizing constructs) at age 13 years were at higher odds for musculoskeletal pain at age 17 years and whether the associations were modified by pubertal status and sex. A prospective cohort design examined data on 3865 adolescents from the Avon Longitudinal Study of Parents and Children (ALSPAC). Associations between baseline (aged 13 years) internalizing and externalizing symptoms and musculoskeletal pain at follow-up (aged 17 years) were investigated using logistic regression producing odds ratios (OR) and 95\% confidence intervals $(95 \% \mathrm{CI})$. In total $43.1 \%$ of adolescents reported musculoskeletal pain at follow-up. Externalizing symptoms at baseline increased the odds of musculoskeletal pain (OR 1.68, 95\% CI 1.28, 2.20), and internalizing symptoms demonstrated a non-significant increase (OR 1.26, 95\% CI 0.98, 1.62). Effect modification analysis showed an increased effect dependent on pubertal status.

Conclusion: Adolescents with externalizing symptoms, and to some extent internalizing symptoms, are at increased odds of later musculoskeletal pain. Future research is now required to understand the reasons for these associations.
\end{abstract}

What is Known:

- Current evidence regarding the association between internalizing symptoms and externalizing symptoms and future musculoskeletal pain in adolescents is mixed.

What is New:

- This study found that adolescents with externalizing symptoms, and to some extent internalizing symptoms, are at increased odds for musculoskeletal pain, with an increased influence dependent on pubertal status.

- These results are of interest for the development of timely preventative interventions designed to reduce the risk of musculoskeletal pain.

Keywords Internalizing $\cdot$ Externalizing $\cdot$ ALSPAC $\cdot$ Prospective study $\cdot$ Musculoskeletal pain $\cdot$ Adolescent

Communicated by Daniele De Luca

Alessandro Andreucci

aa@dcm.aau.dk

Paul Campbell

p.campbell.research@gmail.com

Kate M. Dunn

k.m.dunn@keele.ac.uk
1 Primary Care Centre Versus Arthritis, School of Primary, Community and Social Care, Keele University, Staffordshire ST5 5BG, UK

2 Center for General Practice at Aalborg University, Department of Clinical Medicine, Aalborg University, 9220 Aalborg, Denmark

3 Midlands Partnership NHS Foundation Trust, Department of Research and Innovation, St Georges Hospital, Corporation Street, Stafford, Staffordshire ST16 3SR, UK 


\section{Introduction}

Musculoskeletal pain is common in adolescence, with estimates up to $40 \%$ globally [1]. Adolescent musculoskeletal pain is associated with a high burden in terms of years lived with disability [2] and later musculoskeletal pain in adulthood. Evidence suggests adolescence is a potential sensitive life period for the development of future musculoskeletal pain, and greater understanding is required of potential risk factors at this age [3]. One group of risk factors investigated are psychological symptoms, which are also common in adolescence [4, 5]. Psychological symptoms might exert their effect on musculoskeletal pain through several mechanisms, including a dysfunction of the HPA axis [6-9], an effect on brain regions (amygdala, anterior insula) involved the emotional-affective processing of pain which might result in a decreased pain threshold $[10,11]$ and increased levels of pro-inflammatory cytokines (IL-6, IL-1 $\beta$ and TNF- $\alpha$ ) involved in pain processing [11-13]. Previous studies demonstrated associations between psychological symptoms and musculoskeletal pain, but findings are inconsistent [14-20]. There are several potential explanations for this inconsistency. One is psychological symptom type, with differences reported dependent on whether symptoms are internalizing (e.g. depression and anxiety) or externalizing (e.g. attentiondeficit-hyperactivity disorders and behavioural problems) $[14-16,18,19]$. Another explanation is potential effect modification dependent on sex; one of three studies [17, $19,20]$ investigating sex reported a significant association for internalizing symptoms in girls but not boys, and for externalizing symptoms in boys but not girls [20]. In addition, internalizing symptoms are more common in girls, whereas externalizing symptoms are more common in boys $[4,21]$. A further potential effect modifier is pubertal status; research shows that individuals with advanced pubertal development may be at higher risk for musculoskeletal pain onset [22], and experiencing puberty at a different pace (early or late development) compared to the peer average may increase the risk of developing psychological symptoms [23]. The aim of this study was therefore to prospectively test whether internalizing and externalizing symptoms in adolescents were predictive of musculoskeletal pain and to investigate whether sex and pubertal status modify these associations.

\section{Materials and methods}

\section{Design}

The study was a secondary data analysis of a longitudinal prospective cohort study.

\section{Participants}

The study population was recruited to the Avon Longitudinal Study of Parents and Children (ALSPAC), a birth cohort study. All pregnant women resident in Avon (South West England) who were expected to give birth between 1 Apr. 1991 and 31 Dec. 1992 were eligible to enrol in the study [24]. Information on parents and children was collected during pregnancy and throughout childhood using postal questionnaires and clinical visits [24]. The initial number of pregnant women enrolled, and for which the mother returned at least 1 questionnaire or attended a "Children in Focus" clinic, was 14,541 (see Fig. 1). In the current analysis, adolescents were 13 years old at baseline and 17 years old at follow-up. This selection was made based on the availability of variables. Further information about the study and data collection is described in the study protocol [24]. The ALSPAC study website contains details of all the data (http://www.bristol. ac.uk/alspac/researchers/our-data/).

\section{Measures}

\section{Exposures}

Internalizing and externalizing symptoms were assessed through parent report at baseline using the Strengths and Difficulties Questionnaire (SDQ). The SDQ is a 25 -item questionnaire with five subscales: emotional problems, peer problems, behavioural problems, hyperactivity and prosocial behaviour [25]. Each subscale includes 5 questions rated on a 3-point scale ("Not true" $=0$, "Somewhat true" $=1$, "Certainly true" $=2$ ) producing a score range from 0 to 10 . The emotional problems and peer problems subscales were combined to create the internalizing construct (range 0 to 20), and the behavioural problems and hyperactivity subscales were combined to create the externalizing construct (range 0 to 20). This approach of combining the subscales into broader "internalizing" and "externalizing" constructs has been shown to be suitable and valid for use in epidemiological studies within adolescent cohorts at low risk of psychological symptoms $[26,27]$. A $10 \%$ clinical cut-off was used for defining adolescents with "abnormal" levels of internalizing and externalizing symptoms, in order to identify cases of clinical relevance and reduce the rate of false-positive cases in a low-risk sample, following previous methodology $[25,28]$. The SDQ has shown satisfactory reliability (Cronbach $\alpha, 0.82$; retest stability after 4 to 6 months, 0.72 for the total difficulties scale) [29] and similar performance compared to the Child Behavioural Checklist for the identification of internalizing and externalizing symptoms [30]. 
Fig. 1 Flowchart describing the number of adolescents included in this current study

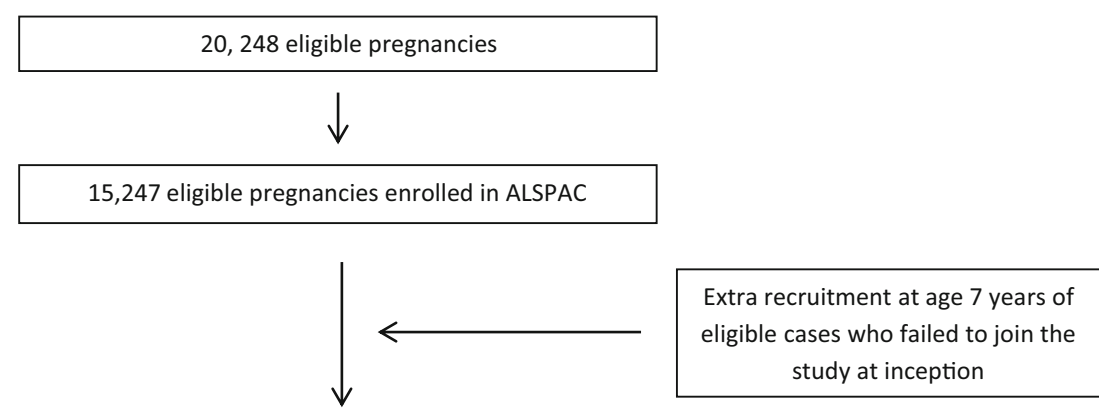

14,541 pregnancies enrolled in ALSPAC for which the mother returned at least 1 questionnaire or attended a "Children in Focus" clinic

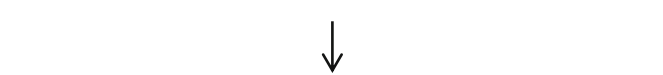

7,062 completed questionnaire at baseline (age 13)

$\downarrow$

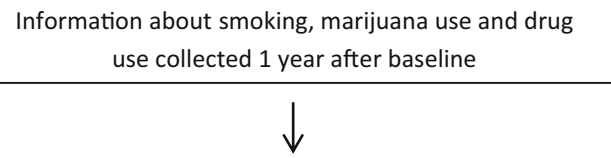

3,865 completed questionnaire at follow-up (age 17)

\section{Outcome}

Pain presence at follow-up was assessed through the question "have you had any aches or pains that have lasted for a day or longer in the past month?" This question was supported by a manikin (pictorial description of body areas that includes two diagrams, one for the front and one for the back) as well as the sentence "Please shade in the diagrams to show where exactly you felt the pain(s)". Pain manikins have previously been shown to be valid and reliable within population cohorts [31-33]. The pain question and manikin response were used to create an outcome variable that represented the presence of musculoskeletal pain at follow-up (pain that related only to the head or abdomen was excluded), following methodology of a previous study carried out with the ALSPAC cohort [34]. Participants were classified as "having musculoskeletal pain" or "not having musculoskeletal pain".

\section{Potential effect modifiers}

Sex and pubertal stage were included as potential effect modifiers. Pubertal stages were measured at baseline using 5-point rating scales and categorized in Tanner stages (from 1 to 5) according to the parental responses. The questionnaire included two scales, and parents indicated the stage (1 to 5) of development their child had reached in each scale. The highest of two ratings (breast development or pubic hair for girls; genital development or pubic hair for boys) was used to indicate the pubertal stage. Adolescents were grouped in the early/ beginning puberty group (Tanner stage $=1$ or 2 ), mid/ advanced puberty group (Tanner stage $=3$ or 4 ) and postpubertal group $($ Tanner stage $=5)$.

\section{Potential confounders}

Potential confounders identified from previous literature were physical activity, smoking, marijuana use and drug use [18, $35,36]$. Parent-reported information on physical activity was gathered at baseline through a questionnaire that included five options of vigorous physical activity (e.g. running, football, swimming, athletics) frequency "none/less than once a week/1-3 times a week/4-6 times a week/daily". Adolescents who performed physical activity "4-6 times a week" or "daily" were considered as having "high levels of physical activity", and those who performed physical activity "none", "less than once a week" or "1-3 times a week" as having "low levels of physical activity". Smoking (yes/no), marijuana use (yes/no) and drug use (yes/no) were selfreported by adolescents at age 14 . 


\section{Data analysis}

Baseline descriptive analysis was performed and values were shown as means and standard deviations (SD) or counts (\%) where appropriate. The association between internalizing and externalizing symptoms (defined as internalizing and externalizing scores $\geq 90$ th percentile) at baseline and musculoskeletal pain at follow-up was assessed by logistic regression producing odds ratios (OR) with $95 \%$ confidence intervals $(\mathrm{CI})$. Associations were adjusted for potential confounders. Potential effect modifiers were examined by statistical interaction test and analysis stratified by sex and pubertal stage. Comparisons were made between stratified groups to observe actual differences in the magnitude or direction of the association between psychological symptoms and musculoskeletal pain across strata of the effect modifier. Potential bias due to missing data was assessed by inspecting the percentage of missingness for each variable, and missing data were replaced through a chained equation multiple imputation method in order to maximize statistical power and increase precision (i.e. to limit the possibility of a biased estimate) [37,38]. All raw variables used in the analysis (i.e. internalizing, externalizing, sex, puberty, physical activity, smoking, marijuana, drug use) were included in the imputation model $[37,38]$. The outcome was included in the imputation model, but not imputed. A number of datasets $(n=35)$ higher than the highest percentage of missing data among the variables (33\% for the variable "puberty") were created [37, 38]. All data was checked for distribution and multicollinearity prior to data analysis. All statistical analyses were carried out using STATA 14.

\section{Results}

\section{Recruitment}

A total of 7062 adolescents were present at baseline, of which $3522(49.9 \%)$ were boys and $3540(50.1 \%)$ girls. At followup, 3865 adolescents responded, representing $54.7 \%$ response.

\section{Participant characteristics}

Table 1 outlines the baseline characteristics of the cohort. The mean and median internalizing scores were $2.6( \pm 2.8)$ and 2 (interquartile range, IQR, 0-17), respectively. Boys and girls had similar mean (boys $2.6 \pm 2.8$, girls $2.7 \pm 2.7$ ) and median (boys (2, IQR, 0-17), girls (2, IQR, 0-15)) internalizing scores and similar proportions above the 90th percentile cutoff (boys $9.7 \%$ vs. girls 9.8\%). The mean and median externalizing scores were $4.2( \pm 3.2)$ and 4 (IQR, 0-18), respectively. Boys had higher mean ( $4.6 \pm 3.3)$ and median (4, IQR,
$0-18$ ) externalizing scores compared to girls (mean $3.7 \pm 2.9$, median 3, IQR, 0-17) and were more likely to be defined as having externalizing symptoms (boys $12.7 \%$ vs. girls $7.2 \%$ ). Girls were in a more advanced pubertal status compared to boys ( $25.9 \%$ vs. $11.0 \%$ in the post-pubertal stage, respectively). Approximately $26 \%$ of adolescents reported having ever tried smoking (18.9\% of boys and $31.3 \%$ of girls), whilst $8.6 \%$ reported having ever tried marijuana (similar between boys and girls). Approximately $15 \%$ of adolescents tried any type of drugs ever, with more girls $(17.7 \%)$ than boys $(12.5 \%)$. Finally, approximately $45 \%$ of adolescents performed physical activity more than 3 times a week, with more boys (53.9\%) than girls (37.6\%). At follow-up, 1666 adolescents $(43.1 \%)$ reported the presence of musculoskeletal pain, whilst 2199 (56.9\%) did not report musculoskeletal pain.

\section{Characteristics of adolescents lost to follow-up}

A total of 3197 adolescents (45.3\%) were lost to follow-up. Those lost were significantly more likely to be boys (54.9\% vs. $41.9 \%)$ and smokers $(27.2 \%$ vs. $22.3 \%)$ and had higher internalizing (10.4\% vs. $8.9 \%)$ and externalizing symptoms ( $12.0 \%$ vs. $7.3 \%$ ) compared to those completing follow-up.

\section{Association between internalizing symptoms at baseline and musculoskeletal pain at follow-up}

Adolescents with internalizing symptoms at baseline were at increased odds of musculoskeletal pain at follow-up, although this association was not significant (adjusted OR 1.26; 95\% CI $0.98,1.62$ ); see Table 2. Stratification by sex showed similar estimates of risk between boys and girls (boys (adj. OR 1.18; 95\% CI 0.81, 1.71), girls (adj. OR 1.34; 95\% CI 0.96, 1.88)); the interaction test was not significant (Table 2). Analysis stratified by pubertal stages showed that the association between internalizing symptoms and musculoskeletal pain was stronger in early pubertal stages than later stages, although this was statistically non-significant (early pubertal stage (adj. OR $=2.27 ; 95 \% \mathrm{CI} 0.99,5.20), \mathrm{mid} /$ advanced pubertal stage $($ adj . $\mathrm{OR}=1.17 ; 95 \% \mathrm{CI} 0.87,1.57$ ), post-pubertal stage (adj. $\mathrm{OR}=$ $1.21 ; 95 \% \mathrm{CI} 0.70,2.10)$ ). The interaction test for puberty was not significant (Table 2).

\section{Association between externalizing symptoms at baseline and musculoskeletal pain at follow-up}

Adolescents with externalizing symptoms at baseline were at significantly higher odds of musculoskeletal pain at follow-up (adj. OR $=1.68 ; 95 \%$ CI 1.28, 2.20); see Table 3. Analysis stratified by sex showed similar estimates of risk in boys and girls (boys (adj. OR 1.88; 95\% CI 1.29, 2.75), girls (adj. OR $1.61 ; 95 \%$ CI $1.09,2.40)$ ), and the interaction test was not significant (Table 3). Further stratified analysis showed that 
Table 1 Baseline sample characteristics

\begin{tabular}{lllll}
\hline Psychological characteristics & Boys & Girls & Overall & Missing \\
\hline Internalizing score (mean \pm SD) & $2.6( \pm 2.8)$ & $2.7( \pm 2.7)$ & $2.6( \pm 2.8)$ & $20.5 \%$ \\
Internalizing score (median, IQR) & $2(0-17)$ & $2(0-15)$ & $2(0-17)$ & \\
Externalizing score (mean \pm SD) & $4.6( \pm 3.3)$ & $3.7( \pm 2.9)$ & $4.2( \pm 3.2)$ & $20.5 \%$ \\
Externalizing score (median, IQR) & $4(0-18)$ & $3(0-17)$ & $4(0-18)$ & \\
Psychological symptoms $>$ 90th percentile & Boys & Girls & Overall & Missing \\
Internalizing & $343(9.7 \%)$ & $346(9.8 \%)$ & $689(9.8 \%)$ & $20.5 \%$ \\
Externalizing & $446(12.7 \%)$ & $256(7.2 \%)$ & $702(9.9 \%)$ & $20.5 \%$ \\
Effect modifiers & Boys & Girls & Overall & Missing \\
Sex & $3168(45.4 \%)$ & $3803(54.6 \%)$ & 6971 & $0 \%$ \\
Pubertal stage & Boys & Girls & Overall & Missing \\
Pre-early puberty & $389(15.8 \%)$ & $240(7.8 \%)$ & $629(11.4 \%)$ & $33.2 \%$ \\
Mid/advanced puberty & $1803(73.2 \%)$ & $2027(66.3 \%)$ & $3830(69.4 \%)$ & $33.2 \%$ \\
Post-puberty & $272(11.0 \%)$ & $791(25.9 \%)$ & $1063(19.2 \%)$ & $33.2 \%$ \\
Confounders & Boys & Girls & Overall & Missing \\
Cigarette smoking (yes) & $489(18.9 \%)$ & $1038(31.3 \%)$ & $1527(25.9 \%)$ & $26.2 \%$ \\
Marijuana smoking (yes) & $216(8.3 \%)$ & $294(8.8 \%)$ & $510(8.6 \%)$ & $25.9 \%$ \\
Drug use ever (yes) & $328(12.5 \%)$ & $592(17.7 \%)$ & $920(15.4 \%)$ & $25.4 \%$ \\
Physical activity $>3$ times $a$ week) & $1490(53.9 \%)$ & $1175(37.6 \%)$ & $2665(45.2 \%)$ & $30.5 \%$ \\
\hline
\end{tabular}

$S D$ standard deviation, $I Q R$ interquartile range the association between externalizing symptoms and musculoskeletal pain was stronger among adolescents in mid/ advanced pubertal stage compared to those at the early or post-pubertal stage (early pubertal stage (adj. OR $=1.20$; 95\% CI 0.48, 3.03), $\mathrm{mid} /$ advanced pubertal stage (adj. OR = $1.85 ; 95 \%$ CI 1.33, 2.57), post-pubertal stage (adj. OR = 1.45; $95 \%$ CI $0.76,2.78)$ ) (Table 3 ). The interaction test for puberty was not significant (Table 3 ).

\section{Discussion}

\section{Main findings}

Psychological symptoms were associated with increased odds of reporting musculoskeletal pain, with a $26 \%$ non-significant increase in odds for internalizing symptoms and a statistically significant $68 \%$ increase for externalizing symptoms. Effect modification analysis showed no effect for sex, but stratification by pubertal status showed some non-significant effect modification trends with increased effect of internalizing in early pubertal stages and increased effect of externalizing in $\mathrm{mid} /$ advanced pubertal stage.

\section{Comparison with previous literature}

Musculoskeletal pain was common in this cohort ( $>40 \%)$, in agreement with findings of other cohorts that used similar pain assessment methods [39]. Whilst previous research has shown mixed effects of psychological symptoms on later adolescent musculoskeletal pain [14-20], there is support for the current findings. Two studies [14, 15] also using the SDQ to evaluate psychological symptoms report a similar significant effect for musculoskeletal pain among those with behavioural problems (part of the externalizing construct), and other recent studies have shown analogous effects using similar birth cohort data [40] and primary care consultation data [41]. However, likefor-like comparison with previous research in adolescent populations can be problematic due to differences in the ages studied, as adolescence is a period of substantial physical and cognitive change $[4,5,23]$, plus differences in psychological symptom measurement [18-20], pain measurement (e.g. different pain sites, acute or chronic pain) $[16,17,20]$ and differences in time intervals between exposure and outcomes [16, 17, 20].

No sex differences were shown in the association between musculoskeletal pain and either internalizing or externalizing symptoms, in agreement with two [17, 19] out of three previous studies where analyses were stratified by sex, suggesting it is not a significant effect modifier. Regarding pubertal status, the time of onset of puberty might increase the risk of psychological symptom development during adolescence [23] and therefore increase the risk of musculoskeletal pain. Results from this current study partly agree with this hypothesis, as different estimates of risk were observed across different pubertal stages (although interaction terms were not significant). However, further research is required to investigate 
Table 2 Logistic regression of the association between internalizing at baseline and musculoskeletal pain at follow-up

\begin{tabular}{|c|c|c|}
\hline \multicolumn{3}{|l|}{ Unadjusted analysis } \\
\hline Musculoskeletal pain at follow-up & Odds ratio & $95 \% \mathrm{CI}$ \\
\hline Overall $(N=3865)$ & 1.17 & $0.92,1.50$ \\
\hline \multicolumn{3}{|l|}{ Adjusted analysis* } \\
\hline Musculoskeletal pain at follow-up & Odds ratio & $95 \% \mathrm{CI}$ \\
\hline Overall $(N=3865)$ & 1.26 & $0.98,1.62$ \\
\hline \multicolumn{3}{|l|}{ Analysis stratified by sex } \\
\hline \multicolumn{3}{|l|}{ Unadjusted analysis } \\
\hline Musculoskeletal pain at follow-up & Odds ratio & $95 \% \mathrm{CI}$ \\
\hline Girls $(N=2245)$ & 1.26 & $0.90,1.75$ \\
\hline Boys $(N=1620)$ & 1.09 & $0.76,1.56$ \\
\hline \multicolumn{3}{|l|}{ Adjusted analysis* } \\
\hline Musculoskeletal pain at follow-up & Odds ratio & $95 \% \mathrm{CI}$ \\
\hline Girls $(N=2245)$ & 1.34 & $0.96,1.88$ \\
\hline Boys $(N=1620)$ & 1.18 & $0.81,1.71$ \\
\hline \multicolumn{3}{|l|}{ Interaction term* } \\
\hline Musculoskeletal pain at follow-up & Odds ratio & $95 \% \mathrm{CI}$ \\
\hline Girls \# internalizing & 1.16 & $0.71,1.89$ \\
\hline \multicolumn{3}{|l|}{ Analysis stratified by pubertal stages } \\
\hline \multicolumn{3}{|l|}{ Unadjusted analysis } \\
\hline Musculoskeletal pain at follow-up & Odds ratio & $95 \% \mathrm{CI}$ \\
\hline Early pubertal stage $(N=378)^{\bullet}$ & 2.13 & $0.97,4.67$ \\
\hline Mid/advanced pubertal stage $(N=2663)^{\bullet \bullet}$ & 1.09 & $0.82,1.46$ \\
\hline Post-pubertal stage $(N=725)^{\bullet \bullet \bullet}$ & 1.09 & $0.63,1.86$ \\
\hline \multicolumn{3}{|l|}{ Adjusted analysis* } \\
\hline Musculoskeletal pain at follow-up & Odds ratio & $95 \% \mathrm{CI}$ \\
\hline Early pubertal stage $(N=378)^{\bullet}$ & 2.27 & $0.99,5.20$ \\
\hline Mid/advanced pubertal stage $(N=2663)^{\bullet \bullet}$ & 1.17 & $0.87,1.57$ \\
\hline Post-pubertal stage $(N=725)^{\bullet \bullet \bullet}$ & 1.21 & $0.70,2.10$ \\
\hline \multicolumn{3}{|l|}{ Interaction term* } \\
\hline Musculoskeletal pain at follow-up & Odds ratio & $95 \% \mathrm{CI}$ \\
\hline Mid/advanced puberty \# internalizing & 0.50 & $0.22,1.17$ \\
\hline $\begin{array}{l}\text { Post-puberty \# internalizing } \\
\text { Reference group: early puberty }\end{array}$ & 0.51 & $0.20,1.30$ \\
\hline
\end{tabular}

- Sample size varies between 378 and 446 as a result of multiple imputation

- Sample size varies between 2663 and 2729 as a result of multiple imputation

•• Sample size varies between 725 and 784 as a result of multiple imputation

*Analysis adjusted for smoking, marijuana use, drug use and physical activity

mechanisms underlying different directions of effect for internalizing and externalizing symptoms.

\section{Strengths and limitations}

A major strength of this study is the prospective cohort design in a large representative population sample of adolescents. This allowed interpretation of findings that can take account of the temporal sequence between exposure and outcome [42], enabled testing of interaction and facilitated adjustment for confounders. Another strength is the examination of potential effect modifiers, which firstly help to untangle the current mixed evidence within the literature and secondly identify adolescent groups at greater or lesser levels of risk. A further strength is the use of the SDQ, which is a valid and suitable measure for the parent report of the adolescents' behavioural and emotional disorders [25, 27, 43, 44]. Some limitations are also present. The musculoskeletal pain measure did not include assessments of pain intensity or function, which may have given a clearer indication of impact [45]. Furthermore, 
Table 3 Logistic regression of the association between externalizing at baseline and musculoskeletal pain at follow-up

\begin{tabular}{|c|c|c|}
\hline \multicolumn{3}{|l|}{ Unadjusted analysis } \\
\hline Musculoskeletal pain at follow-up & Odds ratio & $95 \% \mathrm{CI}$ \\
\hline Overall $(N=3865)$ & 1.78 & $1.37,2.32$ \\
\hline \multicolumn{3}{|l|}{ Adjusted analysis* } \\
\hline Musculoskeletal pain at follow-up & Odds ratio & $95 \% \mathrm{CI}$ \\
\hline Overall $(N=3865)$ & 1.68 & $1.28,2.20$ \\
\hline \multicolumn{3}{|l|}{ Analysis stratified by sex } \\
\hline \multicolumn{3}{|l|}{ Unadjusted analysis } \\
\hline Musculoskeletal pain at follow-up & Odds ratio & $95 \% \mathrm{CI}$ \\
\hline Girls $(N=2245)$ & 1.70 & $1.14,2.51$ \\
\hline Boys $(N=1620)$ & 1.96 & $1.35,2.84$ \\
\hline \multicolumn{3}{|l|}{ Adjusted analysis* } \\
\hline Musculoskeletal pain at follow-up & Odds ratio & $95 \% \mathrm{CI}$ \\
\hline Girls $(N=2245)$ & 1.61 & $1.09,2.40$ \\
\hline Boys $(N=1620)$ & 1.88 & $1.29,2.75$ \\
\hline \multicolumn{3}{|l|}{ Interaction term* } \\
\hline Musculoskeletal pain at follow-up & Odds ratio & $95 \% \mathrm{CI}$ \\
\hline Girls \# externalizing & 0.85 & $0.49,1.47$ \\
\hline \multicolumn{3}{|l|}{ Analysis stratified by pubertal stages } \\
\hline \multicolumn{3}{|l|}{ Unadjusted analysis } \\
\hline Musculoskeletal pain at follow-up & Odds ratio & $95 \% \mathrm{CI}$ \\
\hline Early pubertal stage $(N=378)^{\bullet}$ & 1.33 & $0.55,3.20$ \\
\hline Mid/advanced pubertal stage $(N=2663)^{\bullet \bullet}$ & 1.93 & $1.39,2.68$ \\
\hline Post-pubertal stage $(N=725)^{\bullet \bullet \bullet}$ & 1.54 & $0.81,2.94$ \\
\hline \multicolumn{3}{|l|}{ Adjusted analysis* } \\
\hline Musculoskeletal pain at follow-up & Odds ratio & $95 \% \mathrm{CI}$ \\
\hline Early pubertal stage $(N=378)^{\bullet}$ & 1.20 & $0.48,3.03$ \\
\hline Mid/advanced pubertal stage $(N=2663)^{\bullet \bullet}$ & 1.85 & $1.33,2.57$ \\
\hline Post-pubertal stage $(N=725)^{\bullet \bullet \bullet}$ & 1.45 & $0.76,2.78$ \\
\hline \multicolumn{3}{|l|}{ Interaction term* } \\
\hline Musculoskeletal pain at follow-up & Odds ratio & $95 \% \mathrm{CI}$ \\
\hline Mid/advanced puberty \# externalizing & 1.50 & $0.58,3.89$ \\
\hline $\begin{array}{l}\text { Post-puberty \# externalizing } \\
\text { Reference group: early puberty }\end{array}$ & 1.20 & $0.39,3.68$ \\
\hline
\end{tabular}

- Sample size varies between 378 and 446 as a result of multiple imputation

- Sample size varies between 2663 and 2729 as a result of multiple imputation

-• Sample size varies between 725 and 784 as a result of multiple imputation

*Analysis adjusted for smoking, marijuana use, drug use and physical activity

the same measure for the assessment of musculoskeletal pain was not available at baseline, and this is a major limitation. However, sensitivity analysis with adjustment for an alternative measure of pain collected at baseline (only pain in the arms and/or legs was assessed) showed similar results (available in supplementary file), suggesting that previous pain presence is unlikely to explain the reported effects, notably that externalizing symptoms are associated with later musculoskeletal pain presence. There are limitations with regard to the assessment of puberty. The gold standard is a physical examination, and although parental report is acceptable, some misclassification may be present specifically regarding the accuracy in the pubertal assessment of boys compared to girls [46]. This was a prospective study with a 4-year follow-up, and it was not possible to assess whether the psychological status of adolescents changed between baseline and follow-up (with potential differences among boys and girls) [23]. However, previous studies have used similar approaches with a 4-year follow-up [34, 47], and the gap between measurements is still relevant when taking a long-term or life-course 
approach to studying pain, which is recommended for musculoskeletal pain $[3,48]$. In addition, it might be argued that the presence of chronic diseases and treatments (e.g. complex regional pain syndromes, chronic fatigue syndrome, JIA, diabetes, pharmacological treatments) may have influenced the results found, as they can be associated both with musculoskeletal pain and psychological symptoms [49]. However, given the generally low prevalence of these conditions and treatments at a population level [50-56], this is unlikely to affect the results found. Other additional uncontrolled factors might have affected the results found, such as genetic factors, familiar problems (including socio-economic or health issues) [20, 57-61] and sleep problems, which are associated with musculoskeletal pain in children and adolescents [39, 41]. In addition, whilst we controlled for physical activity at baseline, we cannot exclude that pain was the result of overuse injury or of intensive physical activity sessions in adolescents which might result in transient pain [62-64]. Furthermore, although adjustment for baseline physical activity was applied within the analysis, we were unable to account for any potential changes in physical activity from baseline to follow-up, which has been documented within previous research [65]. Finally, more than $45 \%$ of adolescents were lost to follow-up, and those lost to follow-up were significantly more likely to be boys and smokers and had higher internalizing and externalizing symptoms compared to completers. This may have affected the estimates of association (i.e. towards an underestimation of effect), if those lost to follow-up were at increased odds for musculoskeletal pain compared to those who completed.

\section{Interpretation and implications}

The findings of this study might be interpreted via the biopsychosocial model of pain. From a biological perspective, the stress originating from the presence of psychological symptoms might result in overstimulation of the HPA system and dysfunctional cortisol production [8,66, 67], which has been shown to be associated with pain and increased perception of pain $[8,67]$. Psychological symptoms also affect brain regions (amygdala, anterior insula) involved in the emotionalaffective processing and interpretation of pain, which can decrease the pain threshold $[10,11,68]$. In addition, increased levels of pro-inflammatory cytokines (IL-6, IL-1 $\beta$ and TNF- $\alpha$ ), which contribute to neuro-immune interactions involved in the pain processing [11-13], have been observed after psychological stress in laboratory studies [69] and 2 years after the assessment of internalizing and externalizing symptoms in a study using the ALSPAC cohort [70]. These mechanisms might operate alone or in combination and might be further enhanced by behavioural factors such as rumination and attention, early life adversities (e.g. experiences of physical, emotional and sexual abuse) $[9,71]$ and social factors (low socio-economic status, parental health conditions), which might foster the development of externalizing symptoms that precede musculoskeletal pain [20, 57, 59, 72-75]. At a psychological level, mood symptoms and stress can lead to maladaptive thought processing (catastrophizing and fear avoidance) leading to greater sensitivity to the perception of pain $[76,77]$. Adolescents with externalizing symptoms might also be more physically active and engage in high-risk behaviours (e.g. alcohol consumption, physical conflict with peers) [36], which may increase exposure to activities associated with injury and resulting pain. This study has given greater understanding of the relationship between psychological symptoms and pain development in adolescence and highlighted potential modification effects of puberty. More longitudinal research that can track adolescents over time at multiple time points is now required to understand the causal pathways in order to develop appropriate and timely interventions to reduce the risk of musculoskeletal pain and its recurrence/persistence in adolescents.

\section{Conclusions}

This study found that adolescents with externalizing symptoms are at increased risk of musculoskeletal pain 4 years later. Future research is required to understand the mechanisms that underpin this association, to lay the basis for potential intervention development in this population.

Abbreviations ALSPAC, Avon Longitudinal Study of Parents and Children; SDQ, Strengths and Difficulties Questionnaire; OR, Odds ratio; 95\% CI, $95 \%$ confidence intervals

Supplementary Information The online version contains supplementary material available at https://doi.org/10.1007/s00431-021-04002-5.

Acknowledgements We are extremely grateful to all the families who took part in this study, the midwives for their help in recruiting them and the whole ALSPAC team, which includes interviewers, computer and laboratory technicians, clerical workers, research scientists, volunteers, managers, receptionists and nurses.

Availability of data and materials The dataset analysed for this manuscript is available from the ALSPAC executive committee upon data request.

Authors' Contributions AA, PC and KMD contributed to the design of the analyses. Data analyses were performed by AA. The first version of the manuscript was drafted by AA, PC and KMD. All authors provided substantial intellectual contributions and approved the final version of the manuscript.

Funding The authors disclosed receipt of the following financial support for the research, authorship and/or publication of this article: the UK Medical Research Council and Wellcome (Grant ref: 102215/2/13/2) and the University of Bristol provide core support for ALSPAC. This 
publication is the work of the authors and Alessandro Andreucci, Paul Campbell and Kate Dunn will serve as guarantors for the contents of this paper. A comprehensive list of grants funding is available on the ALSPAC website (http://www.bristol.ac.uk/alspac/external/documents/ grant-acknowledgements.pdf). This research was specifically funded by Wellcome Trust (Grant ref: 084632/Z/08/Z). Alessandro Andreucci was funded by the Keele ACORN studentship. The funding sources had no role in the study design, in the analysis and interpretation of data, in the writing of the report and in the decision to submit the article for publication.

\section{Declarations}

Ethics approval and consent to participate Ethical approval for the study was obtained from the ALSPAC Ethics and Law Committee and the Local Research Ethics Committees. Written informed consent for the use of data collected via questionnaires and clinics was obtained from participants following the recommendations of the ALSPAC Ethics and Law Committee at the time.

Consent for publication Written informed consent for the use of data collected via questionnaires and clinics was obtained from participants following the recommendations of the ALSPAC Ethics and Law Committee at the time.

Competing interests The authors have no conflict of interest to declare that are relevant to the content of this article. Codes used for carrying out the analysis as well as other materials related to the project can be provided upon request to the authors.

Open Access This article is licensed under a Creative Commons Attribution 4.0 International License, which permits use, sharing, adaptation, distribution and reproduction in any medium or format, as long as you give appropriate credit to the original author(s) and the source, provide a link to the Creative Commons licence, and indicate if changes were made. The images or other third party material in this article are included in the article's Creative Commons licence, unless indicated otherwise in a credit line to the material. If material is not included in the article's Creative Commons licence and your intended use is not permitted by statutory regulation or exceeds the permitted use, you will need to obtain permission directly from the copyright holder. To view a copy of this licence, visit http://creativecommons.org/licenses/by/4.0/.

\section{References}

1. King S, Chambers CT, Huguet A et al (2011) The epidemiology of chronic pain in children and adolescents revisited: a systematic review. Pain 152:2729-2738. https://doi.org/10.1016/j.pain.2011. 07.016

2. Mokdad AH, Forouzanfar MH, Daoud F et al (2016) Global burden of diseases, injuries, and risk factors for young people's health during 1990-2013: a systematic analysis for the Global Burden of Disease Study 2013. Lancet 6736:1-19. https://doi.org/10.1016/ S0140-6736(16)00648-6

3. Dunn KM, Hestbaek L, Cassidy JD (2013) Low back pain across the life course. Best Pract Res Rheumatol 27:591-600. https://doi. org/10.1016/j.berh.2013.09.007

4. Merikangas KR, Nakamura EF, Kessler RC (2009) Epidemiology of mental disorders in children and adolescents. Dialogues Clin Neurosci 11:7-20

5. Costello EJ, Copeland W, Angold A (2011) Trends in psychopathology across the adolescent years: what changes when children become adolescents, and when adolescents become adults? J Child Psychol Psychiatry 52:1015-1025. https://doi.org/10.1111/j.14697610.2011.02446.x

6. Generaal E, Vogelzangs N, Macfarlane GJ, Geenen R, Smit JH, Penninx BWJH, Dekker J (2014) Reduced hypothalamicpituitary-adrenal axis activity in chronic multi-site musculoskeletal pain: partly masked by depressive and anxiety disorders. BMC Musculoskelet Disord 15:227. https://doi.org/10.1186/1471-2474$15-227$

7. Gupta A, Silman AJ (2004) Psychological stress and fibromyalgia: a review of the evidence suggesting a neuroendocrine link. Arthritis Res Ther 6:98-106. https://doi.org/10.1186/ar1176

8. McBeth J, Silman AJ, Gupta A, Chiu YH, Ray D, Morriss R, Dickens C, King Y, Macfarlane GJ (2007) Moderation of psychosocial risk factors through dysfunction of the hypothalamicpituitary-adrenal stress axis in the onset of chronic widespread musculoskeletal pain: findings of a population-based prospective cohort study. Arthritis Rheum 56:360-371. https://doi.org/10.1002/art. 22336

9. Hannibal KE, Bishop MD (2014) Chronic stress, cortisol dysfunction, and pain: a psychoneuroendocrine rationale for stress management in pain rehabilitation. Phys Ther 94:1816-1825. https://doi. org/10.2522/ptj.20130597

10. Boakye PA, Olechowski C, Rashiq S, Verrier MJ, Kerr B, Witmans M, Baker G, Joyce A, Dick BD (2016) A critical review of neurobiological factors involved in the interactions between chronic pain, depression, and sleep disruption. Clin J Pain 32:327-336. https:// doi.org/10.1097/AJP.0000000000000260

11. Sluka KA, Clauw DJ (2016) Neurobiology of fibromyalgia and chronic widespread pain. Neuroscience 338:114-129. https://doi. org/10.1016/j.neuroscience.2016.06.006

12. Cook AD, Christensen AD, Tewari D, McMahon SB, Hamilton JA (2018) Immune cytokines and their receptors in inflammatory pain. Trends Immunol 39:240-255. https://doi.org/10.1016/j.it.2017.12. 003

13. Zhou YQ, Liu Z, Liu ZH, Chen SP, Li M, Shahveranov A, Ye DW, Tian YK (2016) Interleukin-6: an emerging regulator of pathological pain. J Neuroinflammation 13:1-9. https://doi.org/10.1186/ s12974-016-0607-6

14. Jones GT, Watson KD, Silman AJ, Symmons DPM, Macfarlane GJ (2003) Predictors of low back pain in British schoolchildren: a population-based prospective cohort study. Pediatrics 111:822-828

15. Jones GT, Silman AJ, Macfarlane GJ (2003) Predicting the onset of widespread body pain among children. Arthritis Rheum 48:26152621

16. Larsson B, Sund AM (2007) Emotional/behavioural, social correlates and one-year predictors of frequent pains among early adolescents: influences of pain characteristics. Eur J Pain 11:57-65

17. Paananen MV, Taimela SP, Auvinen JP, Tammelin TH, Kantomaa MT, Ebeling HE, Taanila AM, Zitting PJ, Karppinen JI (2010) Risk factors for persistence of multiple musculoskeletal pains in adolescence: a 2-year follow-up study. Eur J Pain 14:1026-1032

18. Gill DK, Davis MC, Smith AJ, Straker LM (2014) Bidirectional relationships between cigarette use and spinal pain in adolescents accounting for psychosocial functioning. Br J Health Psychol 19: 113-131

19. Jussila L, Paananen M, Nayha S et al (2014) Psychosocial and lifestyle correlates of musculoskeletal pain patterns in adolescence: a 2-year follow-up study. Eur J Pain 18:139-146

20. Kroner-Herwig B, Gassmann J, van Gessel H, Vath N (2011) Multiple pains in children and adolescents: a risk factor analysis in a longitudinal study. J Pediatr Psychol 36:420-432. https://doi. org/10.1093/jpepsy/jsq099

21. Skounti M, Philalithis A, Galanakis E (2007) Variations in prevalence of attention deficit hyperactivity disorder worldwide. Eur J Pediatr 166:117-123. https://doi.org/10.1007/s00431-006-0299-5 
22. Lardon A, Leboeuf-Yde C, Le Scanff C, Wedderkopp N (2014) Is puberty a risk factor for back pain in the young? a systematic critical literature review. Chiropr Man Ther 22:27. https://doi.org/10.1186/ s12998-014-0027-6

23. Mendle J (2014) Why puberty matters for psychopathology. Child Dev Perspect 8:218-222. https://doi.org/10.1111/cdep.12092

24. Boyd A, Golding J, Macleod J, Lawlor DA, Fraser A, Henderson J, Molloy L, Ness A, Ring S, Davey Smith G (2013) Cohort profile: the 'children of the 90 s'-the index offspring of the Avon Longitudinal Study of Parents and Children. Int J Epidemiol 42: 111-127. https://doi.org/10.1093/ije/dys064

25. Goodman R (1997) The strengths and difficulties questionnaire: a research note. J Child Psychol Psychiatry 38:581-586

26. Goodman A, Lamping DL, Ploubidis GB (2010) When to use broader internalising and externalising subscales instead of the hypothesised five subscales on the Strengths and Difficulties Questionnaire (SDQ): data from British parents, teachers and children. J Abnorm Child Psychol 38:1179-1191. https://doi.org/10. 1007/s10802-010-9434-x

27. Maurice-Stam H, Haverman L, Splinter A, van Oers HA, Schepers SA, Grootenhuis MA (2018) Dutch norms for the Strengths and Difficulties Questionnaire (SDQ) - parent form for children aged 218 years. Health Qual Life Outcomes 16:1-11. https://doi.org/10. 1186/s12955-018-0948-1

28. Goodman R (2001) Psychometric properties of the strengths and difficulties questionnaire. J Am Acad Child Adolesc Psychiatry 40: 1337-1345. https://doi.org/10.1097/00004583-200111000-00015

29. Achenbach TM, Becker A, Döpfner M, Heiervang E, Roessner V, Steinhausen HC, Rothenberger A (2008) Multicultural assessment of child and adolescent psychopathology with ASEBA and SDQ instruments: research findings, applications, and future directions. J Child Psychol Psychiatry Allied Discip 49:251-275. https://doi. org/10.1111/j.1469-7610.2007.01867.x

30. Goodman R, Scott S (1999) Comparing the strengths and difficulties questionnaire and the child behavior checklist: is small beautiful? J Abnorm Child Psychol 27:17-24. https://oi.org/10.1023/A: 1022658222914

31. Margolis RB, Chibnall JT, Tait RC (1988) Test-retest reliability of the pain drawing instrument. Pain 33:49-51

32. Lacey RJ, Lewis M, Jordan K, Jinks C, Sim J (2005) Interrater reliability of scoring of pain drawings in a self-report health survey. Spine (Phila Pa 1976) 30:E455-E458

33. von Baeyer CL, Lin V, Seidman LC et al (2011) Pain charts (body maps or manikins) in assessment of the location of pediatric pain. Pain Manag 1:61-68. https://doi.org/10.2217/pmt.10.2

34. Tobias JH, Deere K, Palmer S, Clark EM, Clinch J (2013) Joint hypermobility is a risk factor for musculoskeletal pain during adolescence: findings of a prospective cohort study. Arthritis Rheum 65:1107-1115

35. Wedderkopp N, Kjaer P, Hestbaek L, Korsholm L, Leboeuf-Yde C (2009) High-level physical activity in childhood seems to protect against low back pain in early adolescence. Spine J 9:134-141

36. Ranney ML, Bromberg J, Hozey A, Casper TC, Mello MJ, Spirito A, Chun TH, Linakis JG, Pediatric Emergency Care Applied Research Network (2018) Problem behaviors and psychological distress among teens seen in a national sample of emergency departments. Acad Pediatr 18:650-654. https://doi.org/10.1016/j. acap.2018.02.016

37. White IR, Royston P, Wood AM (2010) Tutorial in biostatistics multiple imputation using chained equations: issues and guidance for practice. Stat Med 30:377-399. https://doi.org/10.1002/sim. 4067

38. Pedersen AB, Mikkelsen EM, Cronin-Fenton D, Kristensen N, Pham TM, Pedersen L, Petersen I (2017) Missing data and multiple imputation in clinical epidemiological research. Clin Epidemiol 15: 157-166. https://doi.org/10.2147/CLEP.S129785
39. Andreucci A, Campbell P, Mundy LK, Sawyer SM, Kosola S, Patton GC, Dunn KM (2020) Sleep problems increase the risk of musculoskeletal pain in boys but not girls: a prospective cohort study. Eur J Pediatr 179:1711-1719. https://doi.org/10.1007/ s00431-020-03667-8

40. Heikkala E, Paananen M, Taimela S, Auvinen J, Karppinen J (2019) Associations of co-occurring psychosocial and lifestyle factors with multisite musculoskeletal pain during late adolescence a birth cohort study. Eur J Pain 23:1486-1496. https://doi.org/10. 1002/ejp.1414

41. Andreucci A, Campbell P, Richardson E, Chen Y, Dunn KM (2019) Sleep problems and psychological symptoms as predictors of musculoskeletal conditions in children and adolescents. Eur J Pain 24:1-10. https://doi.org/10.1002/ejp.1491

42. Delgado-Rodriguez M, Llorca J (2004) Bias. J Epidemiol Community Health 58:635-641. https://doi.org/10.1136/jech. 2003.008466

43. Mundy LK, Canterford L, Olds T, Allen NB, Patton GC (2017) The association between electronic media and emotional and behavioral problems in late childhood. Acad Pediatr 17:620-624. https://doi. org/10.1016/j.acap.2016.12.014

44. Biel MG, Kahn NF, Srivastava A, Mete M, Banh MK, Wissow LS, Anthony BJ (2015) Parent reports of mental health concerns and functional impairment on routine screening with the strengths and difficulties questionnaire. Acad Pediatr 15:412-420. https://doi.org/ 10.1016/j.acap.2015.01.007

45. Michaleff ZA, Kamper SJ, Stinson JN, Hestbaek L, Williams CM, Campbell P, Dunn KM (2017) Measuring musculoskeletal pain in infants, children, and adolescents. J Orthop Sport Phys Ther 47: 712-730. https://doi.org/10.2519/jospt.2017.7469

46. Coleman L, Coleman J (2002) The measurement of puberty: a review. J Adolesc 25:535-550. https://doi.org/10.1006/jado.2002. 0494

47. Fisher E, Caes L, Clinch J, Tobias JH, Eccleston C (2016) Anxiety at 13 and its effect on pain, pain-related anxiety, and pain-related disability at 17: an ALSPAC cohort longitudinal analysis. Psychol Health Med 21:1-9. https://doi.org/10.1080/13548506.2015. 1051062

48. Dunn KM (2010) Extending conceptual frameworks: life course epidemiology for the study of back pain. BMC Musculoskelet Disord 11:23. https://doi.org/10.1186/1471-2474-11-23

49. Weissmann R, Uziel Y (2016) Pediatric complex regional pain syndrome: a review. Pediatr Rheumatol 14:1-10. https://doi.org/ 10.1186/s12969-016-0090-8

50. Abu-Arafeh H, Abu-Arafeh I (2016) Complex regional pain syndrome in children: incidence and clinical characteristics. Arch Dis Child 101:719-723. https://doi.org/10.1136/archdischild-2015310233

51. Norris T, Deere K, Tobias JH, Crawley E (2017) Chronic fatigue syndrome and chronic widespread pain in adolescence: population birth cohort study. J Pain 18:285-294. https://doi.org/10.1016/j. jpain.2016.10.016

52. Olfson M, Marcus SC, Weissman MM, Jensen PS (2002) National trends in the use of psychotropic medications by children. J Am Acad Child Adolesc Psychiatry 41:514-521. https://doi.org/10. 1097/00004583-200205000-00008

53. Fegert JM, Kölch M, Zito JM, Glaeske G, Janhsen K (2006) Antidepressant use in children and adolescents in Germany. J Child Adolesc Psychopharmacol 16:197-206. https://doi.org/10. 1089/cap.2006.16.197

54. Pettitt DJ, Talton J, Dabelea D, Divers J, Imperatore G, Lawrence JM, Liese AD, Linder B, Mayer-Davis EJ, Pihoker C, Saydah SH, Standiford DA, Hamman RF, for the SEARCH for Diabetes in Youth Study Group (2014) Prevalence of diabetes in U.S. Youth in 2009: the SEARCH for diabetes in youth study. Diabetes Care 37:402-408. https://doi.org/10.2337/dc13-1838 
55. Costello R, McDonagh J, Dixon W et al (2019) Incidence of juvenile idiopathic arthritis in the United Kingdom: estimates from a national primary care dataset. Rheumatology. https://doi.org/10. 1093/rheumatology/kew190.111

56. Harrold LR, Salman C, Shoor S, Curtis JR, Asgari MM, Gelfand JM, Wu JJ, Herrinton LJ (2013) Incidence and prevalence of juvenile idiopathic arthritis among children in a managed care population, 1996-2009. J Rheumatol 40:1218-1225. https://doi.org/10. 3899/jrheum.120661

57. Ramchandani P, Psychogiou L (2009) Paternal psychiatric disorders and children's psychosocial development. Lancet 374:646653. https://doi.org/10.1016/S0140-6736(09)60238-5

58. Ståhl MK, El-Metwally AA, Mikkelsson MK et al (2013) Genetic and environmental influences on non-specific neck pain in early adolescence: a classical twin study. Eur J Pain 17:791-798. https://doi.org/10.1002/j.1532-2149.2012.00247.x

59. Higgins KS, Birnie KA, Chambers CT, Wilson AC, Caes L, Clark AJ, Lynch M, Stinson J, Campbell-Yeo M (2015) Offspring of parents with chronic pain: a systematic review and meta-analysis of pain, health, psychological, and family outcomes. Pain 156: 2256-2266. https://doi.org/10.1097/j.pain.0000000000000293

60. Corley RP, Beltz AM, Wadsworth SJ, Berenbaum SA (2015) Genetic influences on pubertal development and links to behavior problems. Behav Genet 45:294-312. https://doi.org/10.1007/ s10519-015-9719-5

61. Leboeuf-Yde C (2004) Back pain-individual and genetic factors. J Electromyogr Kinesiol 14:129-133. https://doi.org/10.1016/j. jelekin.2003.09.019

62. Aicale R, Tarantino D, Maffulli N (2018) Overuse injuries in sport: a comprehensive overview. J Orthop Surg Res 13:1-11. https://doi. org/10.1186/s13018-018-1017-5

63. Cassas KJ, Cassettari-Wayhs A (2006) Childhood and adolescent sports-related overuse injuries. Am Fam Physician 73:1014-1022

64. Jones GT, Macfarlane GJ (2005) Epidemiology of low back pain in children and adolescents. Arch Dis Child 90:312-316

65. Dumith SC, Gigante DP, Domingues MR, Kohl HW (2011) Physical activity change during adolescence: a systematic review and a pooled analysis. Int J Epidemiol 40:685-698. https://doi.org/ 10.1093/ije/dyq272

66. Chen FR, Raine A, Soyfer L, Granger DA (2015) Interaction of adrenocortical activity and autonomic arousal on children's externalizing and internalizing behavior problems. J Abnorm Child Psychol 43:189-202. https://doi.org/10.1007/s10802-014-9900-y

67. Borsook D, Youssef AM, Simons L, Elman I, Eccleston C (2018) When pain gets stuck: the evolution of pain chronification and treatment resistance. Pain 159:2421-2436. https://doi.org/10. 1097/j.pain.0000000000001401

68. Baliki MN, Apkarian AV (2015) Nociception, pain, negative moods and behavior selection. Neuron 87:474-491. https://doi. org/10.1016/j.neuron.2015.06.005

69. Marsland AL, Walsh C, Lockwood K, John-Henderson NA (2017) The effects of acute psychological stress on circulating and stimulated inflammatory markers: a systematic review and meta-analysis. Brain Behav Immun 64:208-219. https://doi.org/10.1016/j.bbi. 2017.01.011

70. Slopen N, Kubzansky LD, Koenen KC (2013) Internalizing and externalizing behaviors predict elevated inflammatory markers in childhood. Psychoneuroendocrinology 38:2854-2862. https://doi. org/10.1016/j.psyneuen.2013.07.012

71. Frodl T, O'Keane V (2013) How does the brain deal with cumulative stress? A review with focus on developmental stress, HPA axis function and hippocampal structure in humans. Neurobiol Dis 52: 24-37. https://doi.org/10.1016/j.nbd.2012.03.012

72. Henninger WR IV, Luze G (2013) Moderating effects of gender on the relationship between poverty and children's externalizing behaviors. J Child Heal Care 17:72-81. https://doi.org/10.1177/ 1367493512447532

73. Wojtowicz AA, Banez GA (2015) Adolescents with chronic pain and associated functional disability: a descriptive analysis. J Child Heal Care 19:478-484. https://doi.org/10.1177/ 1367493514523157

74. East L, Jackson D, O’Brien L (2006) Father absence and adolescent development: a review of the literature. J Child Heal Care 10:283295. https://doi.org/10.1177/1367493506067869

75. Westrupp EM, Brown S, Woolhouse H, Gartland D, Nicholson JM (2018) Repeated early-life exposure to inter-parental conflict increases risk of preadolescent mental health problems. Eur J Pediatr 177:419-427. https://doi.org/10.1007/s00431-017-3071-0

76. Simons LE, Kaczynski K (2012) The fear avoidance model of chronic pain: examination for pediatric application. J Pain 13: 827-835. https://doi.org/10.1016/j.jpain.2012.05.002

77. Beeckman M, Simons LE, Hughes S, Loeys T, Goubert L (2020) A network analysis of potential antecedents and consequences of pain-related activity avoidance and activity engagement in adolescents. Pain Med 21:e89-e101. https://doi.org/10.1093/pm/pnz211

Publisher's note Springer Nature remains neutral with regard to jurisdictional claims in published maps and institutional affiliations. 